\title{
Twenty-Five Years of No-Touch Saphenous Vein Harvesting for Coronary Artery Bypass Grafting: Structural Observations and Impact on Graft Performance
}

Ninos Samano', MD, PhD; Domingos Souza², MD, PhD; Bruno Botelho Pinheiro ${ }^{3}, \mathrm{MD}, \mathrm{MSc}$; Tomislav Kopjar ${ }^{4}$ MD, PhD; Michael Dashwood ${ }^{5}, \mathrm{PhD}$

DOI: $10.21470 / 1678-9741-2019-0238$

\begin{abstract}
The saphenous vein is the most common conduit used in coronary artery bypass grafting (CABG) yet its failure rate is higher compared to arterial grafts. An improvement in saphenous vein graft performance is therefore a major priority in CABG. No-touch harvesting of the saphenous vein is one of the few interventions that has shown improved patency rates, comparable to that of the left internal thoracic artery. After more than two decades of no-touch research, this technique is now recognized as a Class Ila
\end{abstract}

recommendation in the 2018 European Society of Cardiology and the European Association for Cardio-Thoracic Surgery guidelines on myocardial revascularization. In this review, we describe the structural alterations that occur in conventional versus no-touch saphenous vein grafts and how these changes affect graft patency. In addition, we discuss various strategies aimed at repairing saphenous vein grafts prepared at conventional CABG.

Keywords: Coronary Artery Bypass. Guidelines. Myocardial Revascularization. Saphenous Vein. Mammary Arteries. Cardiology.

Abbreviations, acronyms \& symbols

\begin{tabular}{llll}
\hline ADRF & $=$ Adipocyte-derived relaxing factor & NICE & $=$ National Institute for Health and Care Excellence \\
ADV & $=$ Adventitia & NO & $=$ Nitric oxide \\
C & = Conventional & NT & $=$ No-touch \\
CABG & $=$ Coronary artery bypass grafting & NYHA & $=$ New York Heart Association ok \\
CI & $=$ Confidence interval & OVH & $=$ Open vein harvesting \\
EACTS & $=$ European Association for Cardio-Thoracic Surgery & PVAT & $=$ Perivascular adipose tissue \\
ESC & = European Society of Cardiology & PVF & $=$ Perivascular fat \\
EVH & = Endoscopic vein harvesting & RA & $=$ Radial artery \\
ITA & = Internal thoracic artery & SV & $=$ Saphenous vein \\
L & = Lumen & SVG & $=$ Saphenous vein graft \\
LITA & $=$ Left internal thoracic artery & TM & $=$ Thick media \\
M & $=$ Media & VSMCs & $=$ Vascular smooth muscle cells
\end{tabular}

\section{SAPHENOUS VEIN AS A BYPASS CONDUIT}

In a recent History of Medicine Perspective published in the New England Journal of Medicine, Jones DS ${ }^{[1]}$ outlines the important contribution to coronary artery bypass grafting (CABG) made by Rene Favaloro, who first introduced the saphenous vein (SV) as a conduit for coronary revascularization ${ }^{[2]}$. In the subsequent 50 years, the SV has become the most commonly used graft in patients undergoing $C A B G^{[3,4]}$, yet its failure rate is greater than the one from the left internal thoracic artery (LITA) [5-7]. According to some, it is also inferior to that from the radial
'Department of Cardiothoracic and Vascular Surgery and University Health Care Research Center, Faculty of Medicine and Health, Örebro University, Örebro, Sweden.

2Department of Cardiothoracic and Vascular Surgery, Faculty of Medicine and Health, Örebro University, Örebro, Sweden.

${ }^{3}$ Department Cardiovascular Surgery, Hospital do Coração Anis Rassi, Goiânia, GO, Brazil.

${ }^{4}$ Department of Cardiac Surgery, University of Zagreb School of Medicine and University Hospital Centre Zagreb, Zagreb, Croatia.

${ }_{5}^{5}$ Surgical and Interventional Sciences, Royal Free Hospital Campus, University College London Medical School, London, UK.
This study was carried out at the Department of Cardiothoracic and Vascular Surgery, Örebro University Hospital, Örebro, Sweden.

Correspondence Address:

Ninos Samano

iD https://orcid.org/0000-0003-4249-8401

Department of Cardiothoracic and Vascular Surgery, Örebro University Hospital, Örebro, Sweden.

Postal Code: SE-70185

E-mail: ninos.samano@regionorebrolan.se 
artery $(R A)^{[8-10]}$. Apart from the structural differences between arteries and veins, it is noteworthy that, in general, LITA and RA are harvested in such a way that the pedicle of the surrounding tissue remains intact. When harvesting the saphenous vein graft (SVG), Favaloro's original instructions are followed: "Care must be taken to dissect only the vein, avoiding as much as possible the adventitia that surrounds it"[11]. This method of preparing the SV has become the conventional (C) approach used in most cardiac centres when carrying out CABG. Considerable vascular damage is inflicted when harvesting in such a way that the damage affects vein graft quality and patency. Consequently, affecting clinical prognosis in terms of reoperation rates and long-term survival ${ }^{[12]}$.

Over two decades ago, the 'no-touch' (NT) technique of harvesting SV was introduced ${ }^{[13]}$. Using an atraumatic method, the vein is removed with a pedicle of surrounding tissue and with minimal vascular damage $\mathrm{e}^{[14]}$. Subsequently, a randomized trial comparing C SVG and NT SVG has shown that the latter is superior in terms of patency rates and left ventricular ejection fraction at $1.5,8.5$, and 16 years postoperatively ${ }^{[15-18]}$, as seen in Table 1 from Samano et al. ${ }^{[17]}, 2015$. Furthermore, NT SVGs exhibit a patency comparable to that of LITA at up to 16 years $^{[16,17,19]}$, as seen in Figure 1 from Samano et al. ${ }^{[17]}, 2015$.

Clinical outcomes have also been evaluated. There were significantly more patients free from angina and in New York Heart Association (NYHA) class I in the NT group vs. the C group at 8.5 years postoperatively ${ }^{[20]}$.

These higher patency rates and subsequent clinical advantages have led to the addition of the NT SVG harvesting technique as a Class Ila recommendation in the 2018 European Society of Cardiology (ESC) and the European Association for Cardio-Thoracic Surgery (EACTS) guidelines on myocardial revascularization ${ }^{[21]}$. Many cardiac surgeons in Sweden and Brazil as well as in other countries, including Korea, Japan, Croatia, China, and Russia, now use NT SVGs routinely.

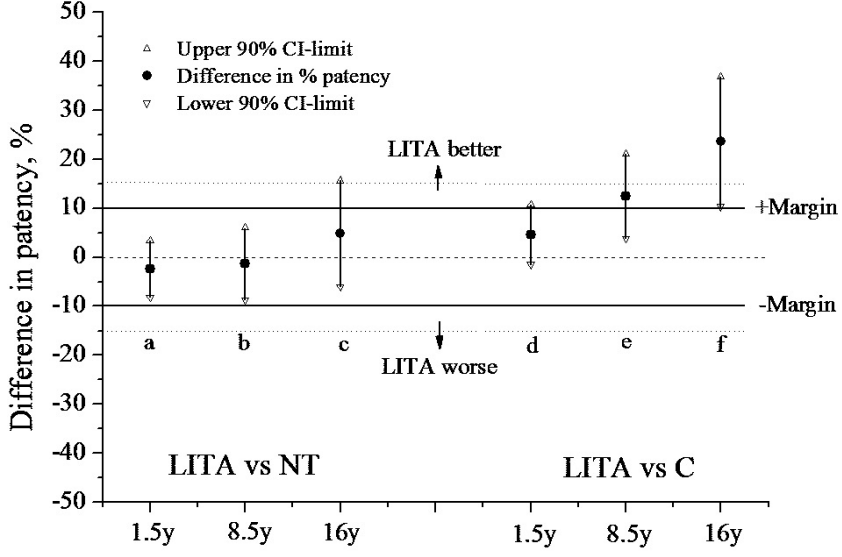

Fig. 1 - Differences in patency, left internal thoracic artery (LITA) vs. no-touch (NT) saphenous vein (SV) and LITA vs. conventional (C) SV at 1.5, 8.5, and 16 postoperative years. The six confidence intervals (a-f) and the margins of 10 and 15 percentage units are the basis for comparing LITA with the SV with respect to potential equivalence and non-inferiority (Samano et al., 2015) ${ }^{[17]}$. Cl=confidence interval.

\section{SAPHENOUS VEIN STRUCTURE AND VASCULAR DAMAGE}

Here we provide an overview of the various aspects of vascular damage that occurs to the SV when using C vs. NT harvesting techniques and we discuss how this may affect the performance of such grafts used in patients undergoing CABG.

The damage to C compared to NT SVGs is obvious on visual examination, as seen in Figure 2 from Kopjar et al. ${ }^{[22]} 2016$. While the surrounding cushion of fat remains intact in NT SVs, it is completely removed in C SVs. In addition, much of the vein's outermost layer, the adventitia, is also removed or damaged. In C

Table 1. Ratio of number of patent grafts to total number of grafts for the two surgical techniques at three follow-up time points (Samano et al. $\left.{ }^{[17]}, 2015\right)$.

\begin{tabular}{|c|c|c|c|c|c|c|c|c|c|}
\hline \multirow[b]{2}{*}{ Follow-up (years) } & \multicolumn{3}{|c|}{ Conventional (C) } & \multicolumn{3}{|c|}{ No-touch (NT) } & \multicolumn{3}{|c|}{ Group difference in \% patency ${ }^{*}$} \\
\hline & 1.5 & 8.5 & 16 & 1.5 & 8.5 & 16 & 1.5 & 8.5 & 16 \\
\hline No. of patients & 46 & 37 & 27 & 45 & 37 & 27 & & & \\
\hline Single grafts & $\begin{array}{c}96 / 107 \\
(90 \%)\end{array}$ & $\begin{array}{l}68 / 87 \\
(78 \%)\end{array}$ & $\begin{array}{l}41 / 63 \\
(65 \%)\end{array}$ & $\begin{array}{c}103 / 109 \\
(94 \%)\end{array}$ & $\begin{array}{l}78 / 87 \\
(90 \%)\end{array}$ & $\begin{array}{l}55 / 67 \\
(82 \%)\end{array}$ & 0.23 & 0.05 & 0.06 \\
\hline Sequential grafts & $\begin{array}{l}16 / 20 \\
(80 \%)\end{array}$ & $\begin{array}{l}10 / 14 \\
(71 \%)\end{array}$ & $\begin{array}{c}5 / 9 \\
(56 \%)\end{array}$ & $\begin{array}{c}15 / 15 \\
(100 \%)\end{array}$ & $\begin{array}{c}14 / 14 \\
(100 \%)\end{array}$ & $\begin{array}{l}7 / 8 \\
(87 \%)\end{array}$ & 0.12 & 0.10 & 0.29 \\
\hline All grafts & $\begin{array}{c}112 / 127 \\
(89 \%)\end{array}$ & $\begin{array}{c}78 / 101 \\
(77 \%)\end{array}$ & $\begin{array}{l}46 / 72 \\
(64 \%)\end{array}$ & $\begin{array}{c}118 / 124 \\
(95 \%)\end{array}$ & $\begin{array}{c}92 / 101 \\
(91 \%)\end{array}$ & $\begin{array}{l}62 / 75 \\
(83 \%)\end{array}$ & 0.08 & 0.01 & 0.03 \\
\hline
\end{tabular}

*Tested with multilevel logistic regression, except for sequential grafts, for which Fisher's exact test had to be used because of small numbers and cells with no occluded grafts. 

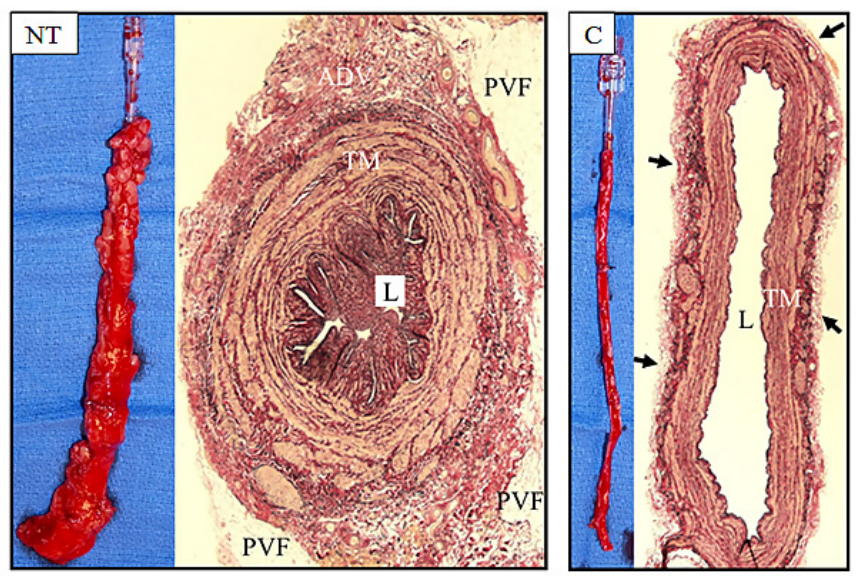

Fig. 2 - Examples of no-touch (NT) and conventional (C) saphenous vein (SV) grafts. The left panels show representative SV explants using both harvesting techniques. NTSV has its surrounding cushion of fat intact and has not been distended. C SV has the fat removed and has been distended to overcome spasm. The transverse section of NT SV shows an intact surrounding cushion of perivascular fat (PVF), an undamaged adventitia (ADV) and thick media (TM). As this vessel has not been distended, the lumen $(L)$ is thrown into folds. The section of C SV exhibits various forms of damage. Much of the ADV has been stripped off, almost to the level of the external elastic lamina (small arrows). The media is thinner than that of the NTSV and L is grossly dilated, both due to high pressure intraluminal distension (Kopjar et al., 2016)[22].

SVs, where SV has been distended at high intraluminal pressure (to overcome spasm), the tunica media is thinner than in nondistended NT SVs. The lumen of NT SV exhibits luminal folding as distension is not required, whereas the lumens of C SVGs are dilated, following high pressure distension. At the microscopic and ultrastructural level, tissue-specific damage and cellular alterations become more obvious, changes that will impact on graft quality and performance. These trauma-induced effects are seen in all three layers (tunica) of SV, the intima, media, and adventitia, as well as the surrounding cushion of perivascular fat.

\section{Endothelium}

This innermost cell layer lining, the intima, is virtually undamaged in NT SVs. This has been demonstrated by immunohistochemistry using endothelium-specific antibodies, a technique that allows quantitative assessment to be performed. In this way, a comparison of the NT SV vs. C SV's endothelial integrity has been reported. Dramatic regions of endothelial denudation were observed in C SVs, resulting in an overall reduction in endothelial integrity ${ }^{[23]}$. This observation was confirmed by assessing the protein expression of CD31, a marker for endothelial cells ${ }^{[24]}$. At the ultrastructural level, striking shape changes of various cells in C SVs vs. NT SVs have been observed ${ }^{[25]}$, as seen in Figure 3 from Ahmed et al. ${ }^{[25]}$, 2004. For example, endothelial cells of NT SVGs remain intact with the nuclei protruding to the lumen and with junctions present between cells whereas those of C SVGs exhibit striking changes, including polymorphism of the endothelium, cells with 'dark' cytoplasm or very thin cell processes protruding towards the vein lumen. Fragments of squamous endothelial cells were abundant in electron-transparent cytoplasmic vesicles. Similar dramatic changes in the appearance of endothelial cells were also observed between NT SVs and C SVs when using scanning electron microscopy ${ }^{[26]}$.

\section{Tunica Media}

Vascular smooth muscle cells (VSMCs) in the media of NT SVS were of a regular arrangement, displaying normal and uniform morphological features and structured appearance, as seen in Figure 3. However, VSMCS in C SVs exhibited polymorphism and the presence of ovoid, elongated, or multi-shaped cells. In addition, the sarcoplasm of some cells was dark ${ }^{[25]}$. Similar ultrastructural observations were reported a decade later ${ }^{[27]}$. Interspersed within the VSMCs of the media is the vasa vasorum, a microvascular network that extends from the adventitia and provides this layer with oxygen and nutrients ${ }^{[28,29]}$. While the vasa vasorum of NT SVs remain intact and patent, those in C SVS exhibited morphological changes and were often occluded by plugging of erythrocytes ${ }^{[25]}$.

\section{Tunica Adventitia}

While this outermost layer of SV is undamaged in NT SVs and the vasa vasorum remains intact, C SVs exhibit obvious signs of damage caused at harvesting and by manipulation by surgical instruments or when using endoscopic vein harvesting (EVH). In addition, the vasa vasorum of C SVs are disrupted, severing the connections to the media and potentially to the SV lumen ${ }^{[26,28-30]}$.

\section{Perivascular Fat}

The pronounced surrounding cushion of perivascular fat that remains intact on NT SVs is completely removed when C SVS are harvested in traditional CABG. This perivascular adipose tissue (PVAT), is comprised mainly of discrete adipocytes that contain a network of capillaries and nerve fibres as well as a variety of other cell types, including macrophages, adipocyte stem/ progenitor cells, lymphocytes, and fibroblasts. These cell types are suggested to possess various beneficial properties that may impact on blood vessel structure and function ${ }^{[31,32]}$.

\section{POTENTIAL CONSEQUENCES OF VASCULAR DAMAGE}

\section{Endothelium}

Damage to each of the layers of the SV may impact on its subsequent performance as a graft. The existence of a variety of endothelium-derived vasoactive factors have been recognised for many years. Of particular relevance to conduits used for revascularisation is nitric oxide (NO), a gaseous, endotheliumderived vasodilator that also possesses antiproliferative, antithrombotic, and anti-inflammatory properties ${ }^{[33]}$. Each of these properties is beneficial to graft performance and therefore damage to the endothelium will have adverse effects 
Fig. 3 - Histological, cellular, and ultrastructural comparison of notouch (NT) vs. conventional (C) saphenous vein (SV) grafts. Top panels are representative examples of part transverse sections through the wall of NT and C SVs stained with Elastic van Gieson and prepared for coronary artery bypass grafting. The intima surrounding lumen (L) of NT SV is thrown into folds. The vein 'wall' is thick with smooth muscle cells of the media (M) separated by the internal and external elastic laminae and with an intact adventitia (ADV) in which the vasa vasorum is located (red arrow). The intimal folds are absent in C SV, the vessel wall is
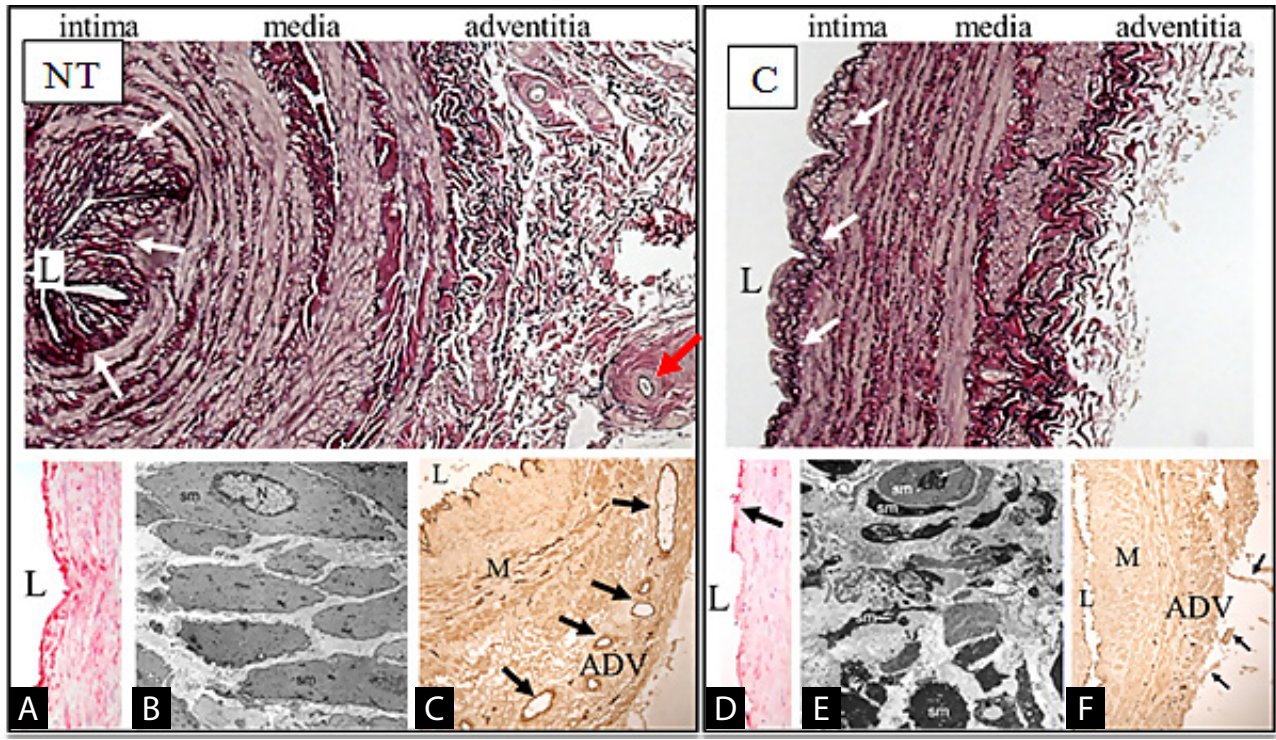
thinner than that from NT SV (due to distension), and the ADV is mostly removed and damaged. The white arrows near vein L indicate the internal elastic lamina. The lower panels show damage caused to C SV when compared to NT SV. Panel A shows an intact endothelial lining of the NT vein L when compared to the C vein shown in panel D. Only a proportion of the endothelial cells in D stain red using the antibody CD31 (arrow). Panel B is a transmission electron micrograph showing the uniform shape and distribution of vascular smooth muscle cells in the M of a NT SV. The appearance of smooth muscle cells in the M of C SV is very different. Panel C shows the wall of a NT SV with an intact vasa vasorum (arrows) within the ADV. The ADV of C SV (F) is mostly removed with remnants indicated by the arrows. Endothelial cells of L and vasa vasorum stain dark brown in these sections with an intact layer lining the NT vein, but regions of denudation present in the C vein. The endothelial cells of the vasa vasorum at the M/ADV border are evident in panel C, but absent in panel F (Ahmed et al., 2004) ${ }^{[25]}$.

on the performance of the SVG used for CABG. Regarding the endothelial damage to C SVGs, the reduction in luminal NO levels would be expected to contribute to the spasm encountered during harvesting. This spasm is caused by surgical trauma when stripping the PVAT. In addition, platelet aggregation and thrombus formation will occur due to reduced local NO at regions of endothelial denudation and exposure of the intima basement membrane, factors involved in early graft failure. Apart from the obvious reduction in wall thickness of C compared with NT SVs, the ultrastructural alterations are striking under transmission electron microscopy ${ }^{[25]}$. The damage to the endothelium of C SVGs may be implicated in various aspects of graft failure, including an effect on intimal/neointimal development, local levels of endothelium-derived vasoactive agents, and platelet activity.

\section{Vascular Smooth Muscle Cells}

The shape changes in VSMCs in C Vs. NT SVs have been confirmed more recently, with evidence that that the molecular fingerprint of VSMC activation is primed in C compared to NT $S V S^{[27]}$. Apart from affecting the reactivity, and therefore flow through SVGs, there is the potential for damaged VSMCs to undergo a phenotype change from 'contractile' to 'synthetic'. This process is involved in neointimal hyperplasia, atheroma formation, and eventual graft occlusion.

\section{Adventitia}

Whereas the adventitia of NT SVs remains intact, in C SVs this layer is severely damaged or almost completely removed. This procedure not only'weakens' the vessel wall, making it more prone to the effect of altered haemodynamics once subjected to coronary arterial conditions, but also damages the vasa vasorum, a situation affecting transmural blood flow ${ }^{[29]}$. It is noteworthy that the vasa vasorum of veins is more pronounced and penetrates deeper into the media than in arteries where the circulating luminal blood supplies oxygen and nutrients. Experimentally, it has been shown that occlusion of adventitial vasa vasorum using a close-fitting external collar reduces or prevents transmural blood flow. This promotes neointimal hyperplasia and atheroma formation ${ }^{[34]}$. Furthermore, neointimal hyperplasia occurs if the adventitia is removed, but regresses on the appearance of 'neoadventitia' ${ }^{\prime[35]}$. These observations suggest that removal of the adventitia and damage to the vasa vasorum in C SVGs are involved in the poor patency rates reported for these veins when compared to the arterial grafts, mainly LITA. However, when using the NT technique, the adventitia and vasa vasorum remain intact and transmural flow is maintained. This has been confirmed where NT SVGs exhibit retrograde filling of the superficial adventitial vasa vasorum after implantation and removal of vascular clamps as well as when isolated segments are perfused with blood via the lumen ${ }^{[29]}$. Apart from histological evidence of damage to the adventitial vasa vasorum, ultrastructural observations show shape 
changes and plugging of erythrocytes in many of the remaining vasa vasorum, mainly within the media ${ }^{[25,29]}$. There is also the possibility that endothelial cells of the vasa vasorum may be involved in endothelial cell migration and subsequent re-endothelialization of regions of the SVG lumen affected at harvesting ${ }^{[29]}$.

\section{Perivascular Fat}

The cushion of surrounding fat that remains intact in NT SVGs may have a number of beneficial effects. Firstly, this cushion possesses a mechanical/supporting role where it acts as a buffer and protects the vein from arterial haemodynamics once implanted into the coronary arterial circulation. In addition, this cushion helps prevent kinking of grafts of excessive length ${ }^{[36]}$ Furthermore, PVAT represents a source of so-called adipocytederived relaxing factor(s) (ADRF), that have potent relaxant or anticontractile properties ${ }^{[31,32]}$. Apart from these actions being demonstrated in blood vessels from experimental animals ${ }^{[37-39]}$, PVAT has been shown to possess anticontractile actions in isolated preparations of the human internal thoracic artery (ITA) ${ }^{[40]}$ and $\mathrm{SV}^{[41]}$. Although specific ADRFs have not yet been identified, various candidates have been suggested, including $\mathrm{NO}^{[42]}$, leptin ${ }^{[32,43]}, \mathrm{H} 2 \mathrm{~S}^{[44]}$, adiponectin ${ }^{[45,46]}$, and prostaglandins $s^{[41,47]}$. Clearly, the removal of such a layer with mechanical/buffering properties as well as a source of factors potentially beneficial to improved graft performance is likely to be inadvisable. It seems that Favaloro's original instructions (1969) ".... to dissect only the vein..." may in some way account for the poor performance of $C$ SVGs in CABG. The question arises; while arterial conduits (ITA and RA) are generally removed with a pedicle intact, why should the SV be harvested with the pedicle removed?

\section{MECHANICAL PROPERTIES OF PERIVASCULAR FAT: WHY USE UNNATURAL EXTERNAL SUPPORT?}

The use of external venous supports in CABG is a strategy introduced over 50 years ago ${ }^{[48]}$. Various forms of external support have been described, ranging from fibrin glue ${ }^{[49]}$ to Dacron ${ }^{T M[50,51]}$ and external mesh ${ }^{[52-54]}$. More recently, an external support made from braided cobalt-chromium-nickel-molybdenum-iron alloy fibers ${ }^{[55-57]}$ has been tested. Based on the results from animal studies, a recent review discusses the proposed mechanisms of action of external SV supports in CABG patients ${ }^{[58]}$. For example, studies into the effect of external synthetic stents and sheaths in a pig model of vein into artery interposition grafting suggest that this form of support has a profound effect on vein graft remodelling and thickening. In addition, external stents inhibit neointima formation and reduce graft thickening via the promotion of angiogenesis in the space between the graft and the sheath or stent ${ }^{[59]}$. Disappointingly, when the results of the 'EXTENT' randomized trial on a small number of CABG patients were analysed, all'EXTENTED' grafts were thrombosed whereas all LIMA grafts and non-stented SVGs remained patent ${ }^{[51]}$. The most recent encouraging data for external vein supports describes the use of braided durable, kink-resistant 'VEST' external stents made of plastically deformable cobalt-chrome wires ${ }^{[58]}$. Here, the placement of VESTs resulted in a significant decrease in mean intimal-medial area with a small decrease in intimal thickness between the stented and control groups. However, these were short-term follow-up studies in small patient numbers.

The main role of the external supports appears to affect mechanisms recognized to play an important role in vein graft performance. Such processes include altered shear stress, VSCM migration, intimal hyperplasia, and atherosclerotic plaque formation. While these processes are involved in graft failure when C SVGs have been used, they are reduced or abolished in vein grafts prepared by the NT technique.

A number of mechanisms have been identified that are suggested to explain the superior performance of SVs harvested by the NT technique ${ }^{[60]}$. Most mechanisms are related to preservation of the outer cushion of fat of the SV acting as'natural support' and therefore sharing the same beneficial properties as those proposed for the various external stents described in the recent review by Mawhinney, Mounsey, and Taggart ${ }^{[58]}$, as seen in Figure 4 from Rueda et al., 2008 ${ }^{[36]}$, and Mawhinney et al., 2017 $7^{[58]}$.
Fig. 4 - Unsupported and supported saphenous vein (SV) grafts for coronary artery bypass grafting. A) An example of a conventionally harvested SV with outermost tissue removed (Rueda et al. ${ }^{[36],}$ 2008). Insert, examples of DacronTM 'EXTENT' and 'VEST' external supports (Mawhinney et al. ${ }^{[58]}$, 2017). B) An example of a no-touch (NT) harvested SV with external tissue intact (Rueda et al. ${ }^{[36],}$ 2008). C) Angiogram of an SV with VEST at 12-month follow-up (Mawhinney et al. $\left.{ }^{[58]}, 2017\right)$. D) NT SV harvesting prevents kinking of excessively long graft (Rueda et al. $\left.{ }^{[36]}, 2008\right)$
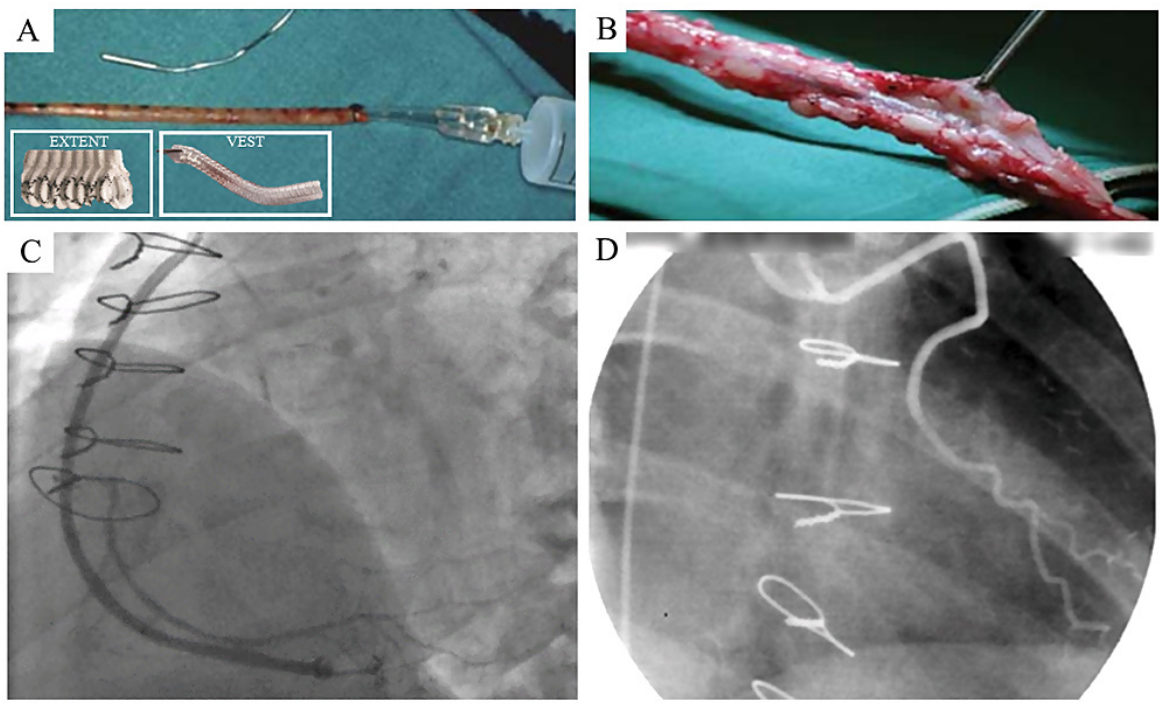
Fig. 5 - Saphenous vein (SV) histology of endoscopic vein harvesting (EVH) vs. no-touch (NT) techniques. Left panel is a transverse section of an SV prepared with $\mathrm{EVH}$. The perivascular layers and endothelium are damaged. The arrow shows intimal tearing (Kiani et al. ${ }^{[69]}, 2011$ ). Middle panel to the left shows a diagram with a small incision above the knee used for insertion of EVH instruments. To the right, it shows a long incision in thigh and calf used for both open vein harvesting and NT harvesting. Right panel is a transverse
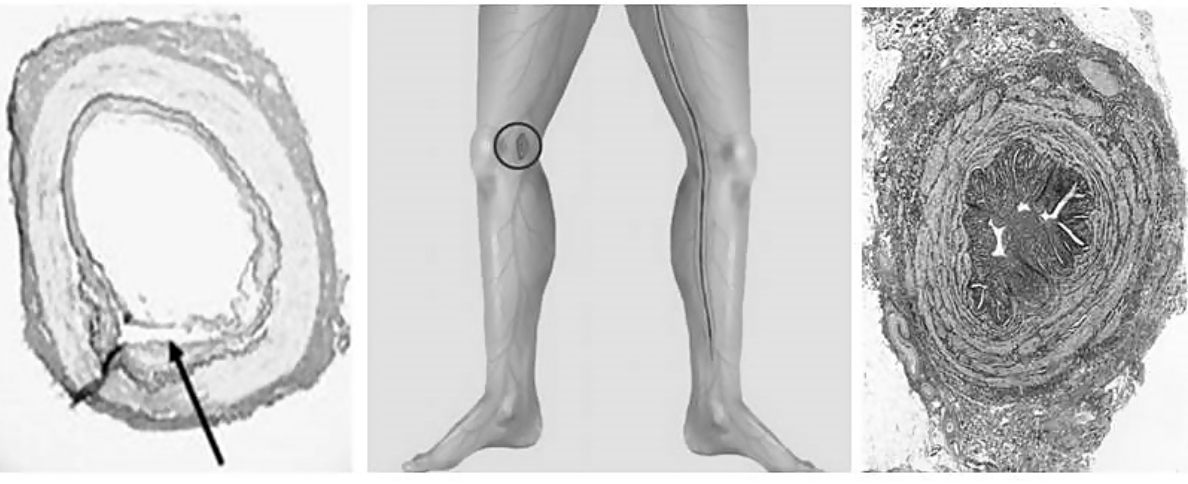
section of a NT harvested SV with perivascular fat and adventitia intact and endothelium undamaged (Kopjar et al. ${ }^{[22], 2016) .}$

The 'protective' properties of the pedicle that is preserved on NT SVGs range from its ability to prevent kinking of long grafts ${ }^{[36,61]}$ and protection of the endothelium ${ }^{[2,24]}$ to the beneficial actions of perivascular fat-derived factors ${ }^{[62,63]}$ and preservation of an intact vasa vasorum ${ }^{[29]}$. Why then use synthetic external supports that may potentially be harmful, complicated, time-consuming to fit, or costly? It seems more logical to remove SV with a'natural' perivascular support intact using the NT technique.

\section{ENDOSCOPIC VEIN HARVESTING}

Minimally invasive $\mathrm{EVH}$ of SV was introduced by Lumsden et al. in the same year as the NT technique ${ }^{[64]}$. This method of harvesting reduces leg wound complications such as infection, pain, and numbness, as well as improving cosmetic results. EVH was rapidly adopted and is now used in many centres worldwide and in the majority of CABG operations in the United States of America ${ }^{[65]}$. Whereas the extensive skin incisions used in open vein harvesting $(\mathrm{OVH})$ allow removal with minimal surgical trauma to the conduit, there is a risk of higher local wound complications. When using either OVH or EVH, the SV should not be grasped with forceps, stretched, or over-distended since endothelial and other forms of vascular damage may affect graft patency. The benefits of EVH and improved wound healing are well accepted, nevertheless there are conflicting reports regarding the patency of SVGs prepared by this method. At best, it appears that the patency of EVH grafts is comparable to those prepared by $\mathrm{OVH}^{[66-}$ ${ }^{69}$. Although $\mathrm{EVH}$ is suggested to be 'minimally invasive' in terms of vessel exposure, wound healing, and scarring, manipulation by instruments and insufflation by $\mathrm{CO}_{2}$ cause considerable vascular trauma. This potentially impacts on the SV's function as a bypass graft ${ }^{[69-71]}$. The damage inflicted effects not only on the endothelium, but also on other parts of the SV, including the intima and adventitia ${ }^{[69,70]}$, as well as the perivascular fat ${ }^{[22]}$, as seen in Figure 5 from Kiani et al., 2011 ${ }^{[69]}$, and Kopjar et al., 2016 [22]. When considering that EVH SVG's patency is, at best, comparable to OVH's patency, it seems reasonable to assume that NT SVGs will be superior to those prepared by EVH. This has been shown in a recent small, short-term study ${ }^{[72]}$. Interestingly, The National Institute for Health and Care Excellence (NICE) previous guidance in the United Kingdom advised that EVH should only be used with special arrangements ${ }^{[73]}$. This was based on data from the PREVENT IV trial where EVH grafts showed higher failure rates than OVH grafts. There was also a higher death rate and more myocardial infarction or revascularization in $\mathrm{EVH}$ vs. OVH grafts at three years postoperatively ${ }^{[74]}$. More recently, based on evidence published subsequently on large numbers of patients, NICE concluded that there was no increased occlusion rates or higher incidences of death, myocardial infarction, or reintervention for endoscopically harvested grafts ${ }^{[75]}$. However, there were comments regarding increased hospital costs for $\mathrm{EVH}$ and the importance of training and regular experience for any clinician doing this procedure (suggested to be up to 30 sessions or more). For more comprehensive reviews on EVH vs. NT SVG see Kopjar and Dashwood, 2016, and Kopjar et al., 2016[22,76].

\section{RATIONALE}

Better management and treatment undoubtedly improve long-term results in many aspects of life. This logic applies, among others, to classic cars, relationships, and to heart surgery. There is no doubt that the NT harvesting technique of SV is less traumatic than the $C$ technique. With the available evidence, preservation of perivascular tissue on the NT SVG conserves normal vessel architecture, protects against distension-induced damage, and maintains endothelial $\mathrm{NO}$, resulting in superior long-term results. Two ongoing multicenter trials, one in China (NCT03126409) ${ }^{[77]}$ and another in Sweden (NCT03501303) will shed further light on the role of NT vein grafts in CABG.

Reliable basic and clinical studies, in addition to logic and reason, have ultimately prevailed with the latest Class Ila recommendation of the NT technique in the 2018 ESC/EACTS guidelines on myocardial revascularization.

\section{No financial support. \\ No conflict of interest.}




\section{Authors' roles \& responsibilities}

NS Substantial contributions to the conception or design of the work; or the acquisition, analysis, or interpretation of data for the work; drafting the work or revising it critically for important intellectual content; agreement to be accountable for all aspects of the work in ensuring that questions related to the accuracy or integrity of any part of the work are appropriately investigated and resolved; final approval of the version to be published

Substantial contributions to the conception or design of the work; or the acquisition, analysis, or interpretation of data for the work; drafting the work or revising it critically for important intellectual content; agreement to be accountable for all aspects of the work in ensuring that questions related to the accuracy or integrity of any part of the work are appropriately investigated and resolved; final approval of the version to be published

BBP Substantial contributions to the conception or design of the work; or the acquisition, analysis, or interpretation of data for the work; drafting the work or revising it critically for important intellectual content; agreement to be accountable for all aspects of the work in ensuring that questions related to the accuracy or integrity of any part of the work are appropriately investigated and resolved; final approval of the version to be published

TK Substantial contributions to the conception or design of the work; or the acquisition, analysis, or interpretation of data for the work; drafting the work or revising it critically for important intellectual content; agreement to be accountable for all aspects of the work in ensuring that questions related to the accuracy or integrity of any part of the work are appropriately investigated and resolved; final approval of the version to be published

MD Substantial contributions to the conception or design of the work; or the acquisition, analysis, or interpretation of data for the work; drafting the work or revising it critically for important intellectual content; agreement to be accountable for all aspects of the work in ensuring that questions related to the accuracy or integrity of any part of the work are appropriately investigated and resolved; final approval of the version to be published

\section{REFERENCES}

1. Jones DS. CABG at 50 (or 107?) -the complex course of therapeutic innovation. N Engl J Med. 2017;376(19):1809-11. doi:10.1056/NEJMp1702718.

2. Captur G. Memento for René Favaloro. Tex Heart Inst J. 2004;31 (1):47.

3. Paez RP, Hossne Junior NA, Santo JADE, Berwanger O, Santos RHN, Kalil RAK, et al. Coronary artery bypass surgery in Brazil: analysis of the national reality through the BYPASS registry. Braz J Cardiovasc Surg. 2019;34(2):142-8. doi:10.21470/1678-9741-2018-0313.

4. Head SJ, Kieser TM, Falk V, Huysmans HA, Kappetein AP. Coronary artery bypass grafting: Part 1--the evolution over the first 50 years. Eur Heart J. 2013;34(37):2862-72. doi:10.1093/eurheartj/eht330.

5. Gaudino M, Taggart D, Suma H, Puskas JD, Crea F, Massetti M. The choice of conduits in coronary artery bypass surgery. J Am Coll Cardiol. 2015;66(15):1729-37. doi:10.1016/j.jacc.2015.08.395

6. Shah PJ, Gordon I, Fuller J, Seevanayagam S, Rosalion A, Tatoulis J, et al. Factors affecting saphenous vein graft patency: clinical and angiographic study in 1402 symptomatic patients operated on between 1977 and 1999. JThorac Cardiovasc Surg. 2003;126(6):1972-7. doi:10.1016/s0022-5223(03)01276-5.

7. Harskamp RE, Lopes RD, Baisden CE, de Winter RJ, Alexander JH. Saphenous vein graft failure after coronary artery bypass surgery: pathophysiology, management, and future directions. Ann Surg. 2013;257(5):824-33. doi:10.1097/SLA.0b013e318288c38d.

8. Gaudino M, Lorusso R, Rahouma M, Abouarab A, Tam DY, Spadaccio C, et al. Radial artery versus right internal thoracic artery versus saphenous vein as the second conduit for coronary artery bypass surgery: a network meta-analysis of clinical outcomes. J Am Heart Assoc. 2019;8(2):e010839. doi:10.1161/JAHA.118.010839.

9. Deb S, Fremes SE. The 3 R's: the radial artery, the right internal thoracic artery, and the race for the second best. JThorac Cardiovasc Surg. 2016;152(4):10924. doi:10.1016/j.jtcvs.2016.06.004.

10. Deb S, Cohen EA, Singh SK, Une D, Laupacis A, Fremes SE, et al. Radial artery and saphenous vein patency more than 5 years after coronary artery bypass surgery: results from RAPS (radial artery patency study). J Am Coll Cardiol. 2012;60(1):28-35. doi:10.1016/j.jacc.2012.03.037.

11. Favaloro RG. Saphenous vein graft in the surgical treatment of coronary artery disease. Operative technique. JThorac Cardiovasc Surg. 1969;58(2):178-85.

12. Fitzgibbon GM, Kafka HP, Leach AJ, Keon WJ, Hooper GD, Burton JR. Coronary bypass graft fate and patient outcome: angiographic follow-up of 5,065 grafts related to survival and reoperation in 1,388 patients during 25 years. J Am Coll Cardiol. 1996;28(3):616-26. doi:10.1016/0735-1097(96)00206-9.

13. Souza D. A new no-touch preparation technique. Technical notes. Scand J Thorac Cardiovasc Surg. 1996;30(1):41-4. doi:10.3109/14017439609107239.

14. Samano N, Pinheiro BB, Souza D. Surgical aspects of no-touch saphenous vein graft harvesting in CABG: clinical and angiographic follow-up at 3 months. Braz J Cardiovasc Surg. 2019;34(1):98-100. doi:10.21470/16789741-2018-0352.

15. Souza DSR, Dashwood MR, Tsui JCS, Filbey D, Bodin L, Johansson B, et al. Improved patency in vein grafts harvested with surrounding tissue: results of a randomized study using three harvesting techniques. Ann Thorac Surg. 2002;73(4):1189-95. doi:10.1016/s0003-4975(02)03425-2.

16. Souza DS, Johansson B, Bojö L, Karlsson R, Geijer H, Filbey D, et al. Harvesting the saphenous vein with surrounding tissue for $C A B G$ provides long-term graft patency comparable to the left internal thoracic artery: results of a randomized longitudinal trial. J Thorac Cardiovasc Surg. 2006;132(2):373-8. doi:10.1016/j.jtcvs.2006.04.002.

17. Samano N, Geijer H, Liden M, Fremes S, Bodin L, Souza D. The no-touch saphenous vein for coronary artery bypass grafting maintains a patency, after 16 years, comparable to the left internal thoracic artery: a randomized trial. JThorac Cardiovasc Surg. 2015;150(4):880-8. doi:10.1016/j.jtcvs.2015.07.027.

18. Johansson B, Samano N, Souza D, Bodin L, Filbey D, Mannion JD, et al. The no-touch vein graft for coronary artery bypass surgery preserves the left ventricular ejection fraction at 16 years postoperatively: long-term data from a longitudinal randomised trial. Open Heart. 2015;2(1):e000204. doi:10.1136/openhrt-2014-000204

19. Samano N, Geijer H, Bodin L, Arbeus M, Mannion JD, Dashwood M, et al. The no-touch saphenous vein graft in elderly coronary bypass patients with multiple comorbidities is a promising conduit to substitute the left internal thoracic artery. J Thorac Cardiovasc Surg. 2017;154(2):457-66.e3. doi:10.1016/j.jtcvs.2017.03.048.

20. Johansson BL, Souza DS, Bodin L, Filbey D, Bojö L. No touch vein harvesting technique for CABG improves the long-term clinical outcome. Scand Cardiovasc J. 2009:43(1):63-8. doi:10.1080/14017430802140104.

21. Neumann FJ, Sousa-Uva M, Ahlsson A, Alfonso F, Banning AP, Benedetto $U$, et al. 2018 ESC/EACTS guidelines on myocardial revascularization. Eur Heart J. 2019;40(2):87-165. doi:10.1093/eurheartj/ehy394.

22. Kopjar T, Dashwood MR. Endoscopic versus "no-touch" saphenous vein harvesting for coronary artery bypass grafting: a trade-off between wound healing and graft patency. Angiology. 2016;67(2):121-32. doi:10.1177/0003319715584126.

23. Tsui JC, Souza DS, Filbey D, Bomfim V, Dashwood MR. Preserved endothelial integrity and nitric oxide synthase in saphenous vein grafts harvested by a 'no-touch' technique. Br J Surg. 2001;88(9):1209-15. doi:10.1046/j.00071323.2001.01855.x.

24. Dashwood MR, Savage K, Tsui JC, Dooley A, Shaw SG, Fernández Alfonso MS, et al. Retaining perivascular tissue of human saphenous vein grafts protects against surgical and distension-induced damage and preserves endothelial 
nitric oxide synthase and nitric oxide synthase activity. J Thorac Cardiovasc Surg. 2009;138(2):334-40. doi:10.1016/j.jtcvs.2008.11.060.

25. Ahmed SR, Johansson BL, Karlsson MG, Souza DSR, Dashwood MR, Loesch A. Human saphenous vein and coronary bypass surgery: ultrastructural aspects of conventional and "no-touch" vein graft preparations. Histol Histopathol. 2004;19(2):421-33. doi:10.14670/HH-19.421.

26. Vasilakis V, Dashwood MR, Souza DS, Loesch A. Human saphenous vein and coronary bypass surgery: scanning electron microscopy of conventional and 'no-touch'vein grafts. Vasc Dis Prev. 2004;1(2):133-9. doi:10.2174/1567270043405204.

27. Verma S, Lovren F, Pan Y, Yanagawa B, Deb S, Karkhanis R, et al. Pedicled no-touch saphenous vein graft harvest limits vascular smooth muscle cell activation: the PATENT saphenous vein graft study. Eur J Cardiothorac Surg. 2014;45(4):717-25. doi:10.1093/ejcts/ezt560.

28. Dashwood MR, Anand R, Loesch A, Souza DS. Hypothesis: a potential role for the vasa vasorum in the maintenance of vein graft patency. Angiology. 2004;55(4):385-95. doi:10.1177/000331970405500405.

29. Dreifaldt M, Souza DS, Loesch A, Muddle JR, Karlsson MG, Filbey D, et al. The "no-touch" harvesting technique for vein grafts in coronary artery bypass surgery preserves an intact vasa vasorum. J Thorac Cardiovasc Surg. 2011;141(1):145-50. doi:10.1016/j.jtcvs.2010.02.005.

30. Souza DS, Christofferson RH, Bomfim V, Filbey D. "No-touch" technique using saphenous vein harvested with its surrounding tissue for coronary artery bypass grafting maintains an intact endothelium. Scand Cardiovasc J. 1999;33(6):323-9. doi:10.1080/14017439950141362.

31. Gollasch M, Dubrovska G. Paracrine role for periadventitial adipose tissue in the regulation of arterial tone. Trends Pharmacol Sci. 2004;25(12):647-53. doi:10.1016/j.tips.2004.10.005

32. Fernández-Alfonso MS, Gil-Ortega M, Aranguez I, Souza D, Dreifaldt M, Somoza $\mathrm{B}$, et al. Role of PVAT in coronary atherosclerosis and vein graft patency: friend or foe? Br J Pharmacol. 2017;174(20):3561-72. doi:10.1111/bph.13734.

33. Moncada S, Palmer RM, Higgs EA. Nitric oxide: physiology, pathophysiology, and pharmacology. Pharmacol Rev. 1991;43(2):109-42.

34. Barker SG, Talbert A, Cottam S, Baskerville PA, Martin JF. Arterial intimal hyperplasia after occlusion of the adventitial vasa vasorum in the pig. Arterioscler Thromb. 1993;13(1):70-7. doi:10.1161/01.atv.13.1.70.

35. Barker SG, Tilling LC, Miller GC, Beesley JE, Fleetwood G, Stavri GT, et al. The adventitia and atherogenesis: removal initiates intimal proliferation in the rabbit which regresses on generation of a 'neoadventitia'. Atherosclerosis. 1994;105(2):131-44. doi:10.1016/0021-9150(94)90043-4.

36. Rueda Fd, Souza D, Lima Rde C, Menezes A, Johansson B, Dashwood M, et al. Novel no-touch technique of harvesting the saphenous vein for coronary artery bypass grafting. Arq Bras Cardiol. 2008;90(6):356-62. doi:10.1590/ s0066-782x2008000600002

37. Li R, Andersen I, Aleke J, Golubinskaya V, Gustafsson H, Nilsson H. Reduced anti-contractile effect of perivascular adipose tissue on mesenteric small arteries from spontaneously hypertensive rats: role of Kv7 channels. Eur J Pharmacol. 2013;698(1-3):310-5. doi:10.1016/j.ejphar.2012.09.026.

38. Agabiti-Rosei C, De Ciuceis C, Rossini C, Porteri E, Rodella LF, Withers SB, et al. Anticontractile activity of perivascular fat in obese mice and the effect of long-term treatment with melatonin. J Hypertens. 2014;32(6):1264-74.

39. Darios ES, Winner BM, Charvat T, Krasinksi A, Punna S, Watts SW. The adipokine chemerin amplifies electrical field-stimulated contraction in the isolated rat superior mesenteric artery. Am J Physiol Heart Circ Physiol. 2016;311 (2):H498507. doi:10.1152/ajpheart.00998.2015.

40. Malinowski M, Deja MA, Janusiewicz P, Golba KS, RolederT,Wos S. Mechanisms of vasodilatatory effect of perivascular tissue of human internal thoracic artery. J Physiol Pharmacol. 2013;64(3):309-16.

41. Ozen G, Topal G, Gomez I, Ghorreshi A, Boukais K, Benyahia C, et al. Control of human vascular tone by prostanoids derived from perivascular adipose tissue. Prostaglandins Other Lipid Mediat. 2013;107:13-7. doi:10.1016/j. prostaglandins.2013.06.002

42. Gil-Ortega M, Stucchi P, Guzmán-Ruiz R, Cano V, Arribas S, González MC, et al. Adaptative nitric oxide overproduction in perivascular adipose tissue during early diet-induced obesity. Endocrinology. 2010;151(7):3299-306. doi:10.1210/en.2009-1464.

43. Abu Bakar H, Robert Dunn W, Daly C, Ralevic V. Sensory innervation of perivascular adipose tissue: a crucial role in artery vasodilatation and leptin release. Cardiovasc Res. 2017;113(8):962-72. doi:10.1093/cvr/cvx062.

44. Bełtowski J. Endogenous hydrogen sulfide in perivascular adipose tissue: role in the regulation of vascular tone in physiology and pathology. Can J Physiol Pharmacol. 2013;91(11):889-98. doi:10.1139/cjpp-2013-0001.

45. Margaritis M, Antonopoulos AS, Digby J, Lee R, Reilly S, Coutinho P, et al. Interactions between vascular wall and perivascular adipose tissue reveal novel roles for adiponectin in the regulation of endothelial nitric oxide synthase function in human vessels. Circulation. 2013;127(22):2209-21. doi:10.1161/CIRCULATIONAHA.112.001133.

46. Shen L, Evans IM, Souza D, Dreifaldt M, Dashwood MR, Vidya MA. Adiponectin: an endothelium-derived vasoprotective factor? Curr Vasc Pharmacol. 2016;14(2):168-74. doi:10.2174/1570161114666151202210128.

47. Mendizábal Y, Llorens S, Nava E. Vasoactive effects of prostaglandins from the perivascular fat of mesenteric resistance arteries in WKY and SHROB rats. Life Sci. 2013;93(25-26):1023-32. doi:10.1016/j.lfs.2013.10.021.

48. Parsonnet V, Lari AA, Shah IH. New stent for support of veins in arterial grafts. Arch Surg. 1963;87(4):696-702. doi:10.1001/archsurg.1963.01310160158031.

49. Stooker W, Niessen HW, Wildevuur WR, van Hinsbergh VW, Fritz J, Jansen EK, et al. Perivenous application of fibrin glue reduces early injury to the human saphenous vein graft wall in an ex vivo model. Eur J Cardiothorac Surg. 2002;21(2):212-7. doi:10.1016/s1010-7940(01)01121-6.

50. Karayannacos PE, Hostetler JR, Bond MG, Kakos GS, Williams RA, Kilman JW, et al. Late failure in vein grafts: mediating factors in subendothelial fibromuscular hyperplasia. Ann Surg. 1978;187(2):183-8. doi:10.1097/00000658-19780200000016.

51. Murphy GJ, Newby AC, Jeremy JY, Baumbach A, Angelini GD. A randomized trial of an external Dacron sheath for the prevention of vein graft disease: the Extent study. JThorac Cardiovasc Surg. 2007;134(2):504-5. doi:10.1016/j. jtcvs.2007.01.092.

52. Human P, Franz T, Scherman J, Moodley L, Zilla P. Dimensional analysis of human saphenous vein grafts: implications for external mesh support. J Thorac Cardiovasc Surg. 2009;137(5):1 101-8. doi:10.1016/j.jtcvs.2008.10.040.

53. Schoettler J, Jussli-Melchers J, Grothusen C, Stracke L, Schoeneich F, Stohn $\mathrm{S}$, et al. Highly flexible nitinol mesh to encase aortocoronary saphenous vein grafts: first clinical experiences and angiographic results nine months postoperatively. Interact Cardiovasc Thorac Surg. 2011;13(4):396-400. doi:10.1510/icvts.2010.265116.

54. Rescigno G, Aratari C, Matteucci SM, Parisi R, Gironi G, Schicchi N, et al. Saphenous vein graft wrapping by nitinol mesh: a word of caution. Thorac Cardiovasc Surg. 2015;63(4):292-7. doi:10.1055/s-0034-1393705.

55. Ben-Gal Y, Taggart DP, Williams MR, Orion E, Uretzky G, Shofti R, et al. Expandable external support device to improve saphenous vein graft patency after CABG. J Cardiothorac Surg. 2013;8(1):122. doi:10.1186/17498090-8-122.

56. Taggart DP, Amin S, Djordjevic J, Oikonomou EK, Thomas S, Kampoli AM, et al. A prospective study of external stenting of saphenous vein grafts to the right coronary artery: the VEST II study. Eur J Cardiothorac Surg. 2017;51(5):952-8. doi:10.1093/ejcts/ezw438. doi:10.1093/ejcts/ezw438.

57. Taggart DP, Webb CM, Desouza A, Yadav R, Channon KM, De Robertis F, et al. Long-term performance of an external stent for saphenous vein grafts: the VEST IV trial. J Cardiothorac Surg. 2018;13(1):117. doi:10.1186/ s13019-018-0803-9.

58. Mawhinney JA, Mounsey CA, Taggart DP. The potential role of external venous supports in coronary artery bypass graft surgery. Eur J Cardiothorac Surg. 2017;53(6):1127-34. doi:10.1093/ejcts/ezx432.

59. Jeremy JY, Gadsdon P, Shukla N, Vijayan V, Wyatt M, Newby AC, et al. On the biology of saphenous vein grafts fitted with external synthetic sheaths and stents. Biomaterials. 2007;28(6):895-908. doi:10.1016/j. biomaterials.2006.10.023.

60. Dashwood MR, Tsui JC. 'No-touch'saphenous vein harvesting improves graft performance in patients undergoing coronary artery bypass surgery: a journey from bedside to bench. Vascul Pharmacol. 2013;58(3):240-50. Erratum in:Vascul Pharmacol. 2013;59(1-2):52. doi:10.1016/j.vph.2012.07.008.

61. Souza DS, Arbeus M, Botelho Pinheiro B, Filbey D. The no-touch technique of harvesting the saphenous vein for coronary artery bypass grafting surgery. Multimed Man Cardiothorac Surg. 2009;2009(731):mmcts.2008.003624. doi:10.1510/mmcts.2008.003624

62. Fernandez-Alfonso MS, Souza DS, Dreifaldt M, Dashwood MR. Commentary: 
perivascular fat and improved vein graft patency in patients undergoing coronary artery bypass surgery. Curr Vasc Pharmacol. 2016;14(4):308-12. doi:10.2174/1570161114666160513150444.

63. Lumsden AB, Eaves FF 3rd, Ofenloch J, Jordan W. Subcutaneous, videoassisted saphenous vein harvest: report of the first 30 cases. Cardiovasc Surg. 1996;4(6):771-6. doi:10.1016/s0967-2109(96)00055-5.

64. Dacey LJ, Braxton JH Jr, Kramer RS, Schmoker JD, Charlesworth DC, Helm RE, et al. Long-term outcomes of endoscopic vein harvesting after coronary artery bypass grafting. Circulation. 2011;123(2):147-53.

65. Zenati MA, Bhatt DL, Bakaeen FG, Stock EM, Biswas K, Gaziano JM, et al. Randomized trial of endoscopic or open vein-graft harvesting for coronary-artery bypass. N Engl J Med. 2019;380(2):132-41. doi:10.1056/ NEJMoa1812390.

66. Krishnamoorthy B, Critchley WR, Thompson AJ, Payne K, Morris J, Venkateswaran RV, et al. Study comparing vein integrity and clinical outcomes in open vein harvesting and 2 types of endoscopic vein harvesting for coronary artery bypass grafting: the VICO randomized clinical trial (vein integrity and clinical outcomes). Circulation. 2017;136(18):1688-702. doi:10.1161/CIRCULATIONAHA.117.028261.

67. Yun KL, Wu Y, Aharonian V, Mansukhani P, Pfeffer TA, Sintek CF, et al. Randomized trial of endoscopic versus open vein harvest for coronary artery bypass grafting: six-month patency rates. J Thorac Cardiovasc Surg. 2005;129(3):496-503. doi:10.1016/j.jtcvs.2004.08.054.

68. Perrault LP, Jeanmart H, Bilodeau L, Lespérance J, Tanguay JF, Bouchard D, et al. Early quantitative coronary angiography of saphenous vein grafts for coronary artery bypass grafting harvested by means of open versus endoscopic saphenectomy: a prospective randomized trial. J Thorac Cardiovasc Surg. 2004;127(5):1402-7. doi:10.1016/j.jtcvs.2003.10.040.

69. Kiani S, Poston R. Is endoscopic harvesting bad for saphenous vein graft patency in coronary surgery? Curr Opin Cardiol. 2011;26(6):518-22. doi:10.1097/HCO.0b013e32834b9f6d.
70. Kiani S, Desai PH, Thirumvalavan N, Kurian DJ, Flynn MM, Zhao X, et al. Endoscopic venous harvesting by inexperienced operators compromises venous graft remodeling. Ann Thorac Surg. 2012;93(1):11-7; discussion 7-8. doi:10.1016/j.athoracsur.2011.06.026.

71. Kodia K, Patel S, Weber MP, Luc JGY, Choi JH, Maynes EJ, et al. Graft patency after open versus endoscopic saphenous vein harvest in coronary artery bypass grafting surgery: a systematic review and meta-analysis. Ann Cardiothorac Surg. 2018;7(5):586-97. doi:10.21037/acs.2018.07.05.

72. Mannion JD, Marelli D, Brandt T, Stallings M, Cirks J, Dreifaldt M, et al. "Notouch" versus "endo" vein harvest: early patency on symptom-directed catheterization and harvest site complications. Innovations (Phila). 2014;9(4):306-11. doi:10.1097/IMI.0000000000000084.

73. Barnard JB, Keenan D. Endoscopic saphenous vein harvesting for coronary artery bypass grafts: NICE guidance. Heart. 2011;97(4):327-9. doi:10.1136/ hrt.2010.209668.

74. Lopes RD, Hafley GE, Allen KB, Ferguson TB, Peterson ED, Harrington RA, et al. Endoscopic versus open vein-graft harvesting in coronary-artery bypass surgery. N Engl J Med. 2009;361(3):235-44. doi:10.1056/NEJMoa0900708.

75. NICE. Endoscopic saphenous vein harvest for coronary artery bypass grafting. Interventional procedures guidance [IPG494] [Internet]. England [UK]: National Institute for Health and Care Excellence.; 2014 [cited 2019 Nov 26]. Available from: https://www.nice.org.uk/guidance/ipg494/chapter/1recommendations.

76. Kopjar T, Ivankovic S, Lima ML, Pinheiro BB, Dashwood MR. Endoscopic or no-touch vein harvesting for CABG: what is best for the patient? Braz J Cardiovasc Surg 2016;31(6):461-4. doi:10.5935/1678-9741.20160091.

77. Wang XQ, Tian MC, Zheng Z, Gao HW, Wang Y, Wang LQ, et al. Rationale and design of a multicenter randomized trial to compare the graft patency between no-touch vein harvesting technique and conventional approach in coronary artery bypass graft surgery. Am Heart J. 2019;210:75-80. doi:10.1016/j.ahj.2018.11.011. 